\title{
Amoxicillin Induced Immediate Allergic Reaction- A Case Report
}

\author{
Ashok Kumar Malpani*, Riyaz Miya, Praveen Teja, Brahmadi Shankar Reddy \\ Department of Pharmacy Practice, Gulbarga Instutute of Medical Sciences Hospital, Kalaburgai, RMES College of Pharmacy, \\ Kalaburagi, Karnataka, INDIA.
}

\section{ABSTRACT}

Amongst antibiotics, amoxicillin is oftentimes prescribed to oppugn array of infections. Penicllins are well recognised for their drug induced cutaneous eruptions substantially in paediatric population. This case is being promulgated to strengthen the evidence against amoxicillin induced skin reactions.

Key words: Amoxicillin, Cutaneous, Penicillin, Paediatrics.

\section{INTRODUCTION}

Amoxicillin considered as the mainstay of treatment in Community acquired bacterial infections (CABI) in infants, which is frequently prescribed and considered to be the best drug of choice due to its superior absorptive nature followed by oral route when compared to other Beta-lactam congeners. ${ }^{1,2}$ Beta-lactams regardless of their origin whether it may be naturally produced or synthetic or semi synthetic are susceptible to provoke immediate or nonimmediate allergic reactions. ${ }^{3}$ In recent past many articles in the form of case reports and case series have been published regarding amoxicillin induced skin rashes. ${ }^{4}$ Here we are reporting a case of non-immediate maculopapular, erythematous rash induced by amoxicillin/clavulanate.

\section{CASE REPORT}

A one year seven days old male baby was admitted to the paediatric ward of Gulbarga Institute of Medical Science Hospital with complaints of hyperthermia from three to four days and multiple abscess on head since one month. The baby was prescribed with the oral syrup Amoxicillin/clavulanate which is $3.3 \mathrm{gm} / 30 \mathrm{ml}$ and administered as $2.5 \mathrm{ml} / \mathrm{BD}$ and syrup Paracetamol which is $125 \mathrm{mg} / 5 \mathrm{ml}$ and administered as $2.5 \mathrm{ml} /$
TID. After having second dose amoxicillin clavulonate with an interval of $8 \mathrm{hr}$ to $10 \mathrm{hr}$, the baby started developing itching and had maculopapular reaction over the trunk within half an hour which was also disseminated to neck, limb and abdomen as dipicted in Figure 1 by observing the baby's situation, it was considered to discontinue the treatment with amoxicillin and clauvanate and advised to switch on to syrup cetirizine and calamine lotion as local applicant to relieve from rashes and control further allergy. On examination, patient was conscious, oriented and stable with pulse rate of $94 / \mathrm{min}$. As a part of counselling, regarding the baby's past history, the parents has revealed that same such instance has encountered with similar reaction 15 days back. It was also found that it was due to the same medication i.e. amoxicillin and clauvanate which was prescribed by local physician. By considering the above facts we have assessed the present data on Naranjo's causality assessment scale for which the outcome obtained from it was definite.

\section{DISCUSSION}

As a part of our daily routine pre-ward rounds, we came across a case of macopapular skin rashes on neck and back portion of male
DOI: 10.5530/ijopp.13.2.30

Address for correspondence: Dr. Ashok Kumar Malpani Department of Pharmacy Practice, Gulbarga Instutute of Medical Sciences Hospital, Kalaburgai, RMES College of Pharmacy, Kalaburagi-585102, Karnataka, INDIA.

Phone no: + 919845407765 Email Id: bsreddi2005@gmail. com

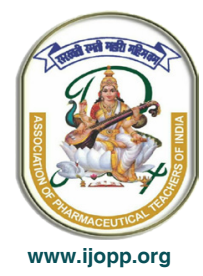




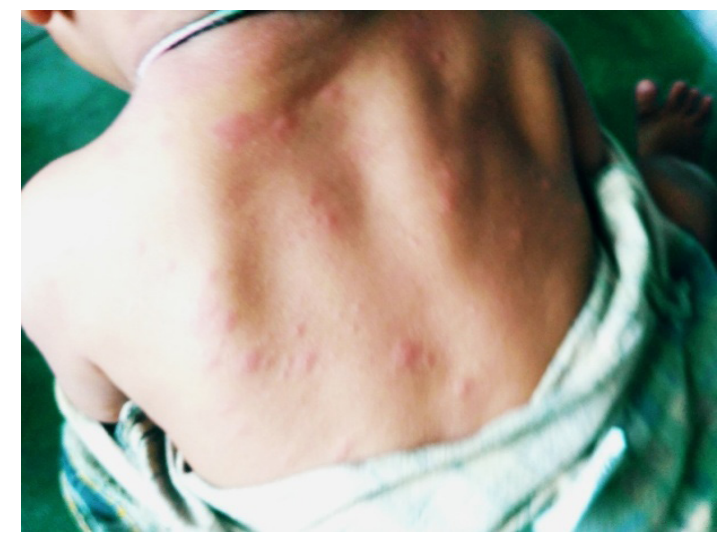

Figure 1: Maculopular erythamatous rashes.

baby. These macopapular rashes were found

to be crimson red in colour with mild itchy in nature as well. The reason for this was found to be drug induced macopapular rashes by amoxicillin/clavulonate. it was observed that around $10 \%$ of population treated with betalactams were prone to such allergic reaction which were reported in India and elsewhere. ${ }^{5}$ Amoxicillin (Penicillins) induced skin reactions are said to be Classic in nature which are interceded by involvement of Immune system and categorised to immediate (developing within half an hour to one hour of drug ingestion) and non-immediate (beyond one hour of ingestion). ${ }^{2}$ The present case study has shown new insights regarding the role of clinical pharmacist's intervention in finding such scenarios. Apart from this clinical pharmacist as a drug expert can share his/her views and experience with other health care providers regarding better pharmaceutical care provided to the patient. Drug alert card can help the patient preventing from such reactions in future too.

\section{CONCLUSION}

From the present case report it shows the lacunas of prescribers knowledge regarding the assessment of cutaneous eruptions associated with beta-lactams which has a lion's share of prescriptions in pediatric department for majority of bacterial infections. It also suggests that clinical pharmacist has a pivotal role in health care sector particularly in the given situation as an exemplary.

\section{REFERENCES}

1. Weisser C, Ben-Shoshan M. Immediate and non immediate allergy reactions to amoxicillin present a diagnostic dilemma: A case series. Journal of Medical Case Reports. 2016;10(10):1-5.

2. Jaykare SC, Motghare VM, Padwal SL, Patil JR, Pise HN. Cutaneous drug eruption caused by amoxicillin: A case report. Indian Journal of Clinical Practice. 2016;24(3):230-2.

3. Jetwa S. Penicillin allergy identification and management: Hypersensitivity and Allergy. The Pharmaceutical Journal. 2015;295(7878):1-9.

4. Caubet JC, Kaiser L, Lemaitre B, Fellay B, Gervaix A, Eigenmann PA. The role of penicillin in benign skin rashes ii childhood: A prospective study based on drug re-challenge. J Allergy Clin Immunol. 2011;127(1):218-22.

5. Ponvert C, Clainche LL, DeBlic J, Bourgeois ML, Scheinmann P, Paupe J. Allergy to betalactam antibiotics in children. American Academy of Paediatrics. 1999;104(4):1-9. 